\title{
LXXI. A comparison of the periods of the electrical vibrations associated with simple circuits
}

\author{
J.A. Pollock \& J.C. Close
}

To cite this article: J.A. Pollock \& J.C. Close (1904) LXXI. A comparison of the periods of the electrical vibrations associated with simple circuits, Philosophical Magazine Series 6, 7:42, 635-655, DOI: $10.1080 / 14786440409463158$

To link to this article: http://dx.doi.org/10.1080/14786440409463158

曲 Published online: 15 Apr 2009.

Submit your article to this journal $\square$

Џ Article views: 3

Q View related articles $\square$

Citing articles: 1 View citing articles $\square$ 


\section{$[635]$}

LXXI. A Comparison of the Periods of the Electrical Vibrations associated with Simple Circuits. By J. A. Pollock, Professor of Plyysics in the University of Sydney. With an Appendix by J. C. Close, Leas-Thomson Scholar in Physics*.

\section{Introductory.}

THE object of the present research has been to compare the periods of the electrical vibrations connected with narrow rectangular closed circuits with those of the oscillations associated with straight wires and with open and closed rings.

The essential features of the experimental method adopted are as follows:-A condenser is discharged in the neighbourhood of a narrow rectangular closed circuit; oscillatory currents are thus set up in the rectangle, which in turn induce others in a third circuit of required shape. Observations of the amplitudes of the disturbances in the circuitare made with Rutherford's magnetic detectors, while the dimensions of the circuits are adjusted, step by step, until finally all three are in tune. The length of a circuit of any shape can thus be found which has the same period of electrical vibration as that of a given narrow rectangular closed circuit.

When the experiments were commenced, it was generally considered, on theoretical grounds, that the wave-length of the free oscillation connected with open resonators was equal to twice the length of the circuit $\dagger$; and certain experimental evidence had lately been published $\ddagger$ which apparently accorded with such a view. The well-known experiments of Sarasin and De la Rive and others, however, make the wavelength greater than twice the length of the resonator. It seemed essential therefore to strengthen, if possible, the experimental position, and with this object in view the present experiments were undertaken. Since their practical completion, theoretical support has been withdrawn from the results first mentioned, by the publication of Macdonald's Adams Prize Essay on Electric Waves (Cambridge, 1902), which has wholly changed the theoretical aspect.

Macdonald's calculations so closely agree with the bulk of

* Communicated by the Author. Read before the Royal Society of New South Wales.

† Kirchhoff, Pogg. Ann. vol. exxi., 1864. Thomson, 'Recent Researches,' p. 340 (1893). Poincuré, 'Les Oscillations Electriques', p. 273 (G. Carré, Paris, 1894).

† Turpain, Journ. de Phys. rol. x. p. 425 (1901); Slaby, Electrotech. Zeit. No. 9, p. 165 (1902). 
the experimental evidence, that there can no longer be any doubt that the wave-length of the free oscillation associated with open circuits is considerably greater than twice the length of the wire.

\section{General Results.}

Open Circuits.-A. Slaby (Electrotech. Zeit. No. 9, p. 165, 1902 ) has investigated with a spark-micrometer the potential at various points of a straight wire when electrical vibrations take place along it. $\mathrm{He}$ finds a stationary wave with potential loops at the ends, and a relative node at the middle. Such an experiment does not seem calculated to determine the actual wave-length of the vibration connected with the wire, but apparently Dr. Slaby is satisfied, from a consideration of the observations, that the wave-length of the oscillation is equal to twice the length of the wire. He has also theoretically discussed the problem, and "the calculation gives a full confirmation of the experimental results." The experiments were made with wires from one to ten metres long.

Drude, in Ann. der Phys. ix. 2, p. 293 (1902), publishes an account of an elaborate research on the vibration-period and self-induction of wire coils, in connexion with the construction of Tesla transformers. On page 328 he gives the results of the investigation with coils with few windings and with single circles. Drude does not measure the period of the vibration connected with straight wires, but states that for a thin straight wire the half wave-length is equal to the length of the wire. He refers to a calculation of Abraham (Wied. Ann. vol. Ixvi. p. 471, 1898) which gives the half wavelength 0.85 per cent. greater than the wire-length, for a straight wire $0.25 \mathrm{~cm}$. in diameter and $77 \mathrm{cms}$. long.

In the present experiments, the comparison of the periods has been made in all cases between circuits constructed of copper wire $0.33 \mathrm{~cm}$. in diameter and rectangles of thin brass wire $0.04 \mathrm{~cm}$. thick, the rectangles being $30 \mathrm{cms}$. wide.

It is found that the perimeters of the rectangles are greater than twice the length of straight wires which have the same period of electrical vibration, the ratio of the lengths varying from $2 \cdot 45$ for a rectangle $760 \mathrm{cms}$. in perimeter, to $2 \cdot 31$ for one whose perimeter is $1200 \mathrm{cms}$.

Approximately at least, the wave-length of the electrical vibration associated with narrow rectangular closed circuits may be taken as equal to the perimeters of the rectangles. It appears then from these experiments, that the wave-length 
of the oscillation connected with a straight wire is much greater than twice the length of the wire, a result opposed to Slaby's conclusions and to Drude's statement.

For open circular resonators Sarasin and De la Rive* obtain results which are usually stated by saying that the wavelength of the free electrical oscillation connected with such circuits is equal to eight times the diameter of the circuit or to $2 \cdot 55$ times the wire-length. These results have been abundantly verified in a general sense, but it is doubtful if the statement is not too wide, as it takes no account of the diameter of the wire of which the resonator is made, nor of the shape or configuration of the ends of the circuit.

Turpain, from observations published quite recentily, arrives at a different conclusion. He has investigated the problem of the vibration connected with circular resonators in an ingenious manner, by inclosing them in exhausted glass tubes, and judging of the electrical state of the wires by the luminosity produced in the rarefied gas. Turpain has published many accounts of his experiments, finally summarizing his work in the Journal de Plysique, vol. x. p. 425 (1901). On p. 435 et seq. he describes experiments made with an open circular resonator and part of the inducing field inclosed in an exhausted vessel, and others where only the spark-gap. was surrounded with rarefied gas. In both cases, it is stated that the resonator responds when one half the exciting wavelength is equal to the length of the resonator. Turpain considers it experimentally established that "the length of the wave of the electrical oscillation which excites a wireformed resonator is equal (allowance being made for the micrometer perturbation) to double the length of the resonator." That a perturbation set up at the spark-gap is not, however, responsible for any apparent discrepancy between theory and experiment, was shown by the work of Strindberg $\dot{\dagger}$, who confirmed Sarasin \& De la Rive's results with a resonator in which no spark occurred. If Turpain has interpreted his experiments aright, his results must be considered at variance with the great body of experimental evidence and with present theory.

Drude (loc. cit.p. 330) gives the measures of the wave-length of the vibration connected with four open circles, three of them being supported by wooden cores and one being wholly surrounded by air. For the latter, the half wave-length is $259 \mathrm{cms}$. when the length of the wire is $243 \mathrm{cms}$., the ratio

* Sarasir \& De la Rive, C. $R$. vol. cx. 1890, vol. cxii. 1891, vol, cxv. 1892.

$\dagger$ Strindberg, C. R. vol. cxxii. p. 1403 (1896). 
being $1 \cdot 065$. Drude concludes from this experiment that "the half natural wave-length of a nearly closed thin wire circle is 6.5 per cent. greater than its length." This value I believe to be far too small.

With the circuits used, the present experiments give for the ratio of the perimeters of rectangles $30 \mathrm{cms}$. in width to the lengths of open circular circuits, when both have the same period of vibration, values varying from $2 \cdot 38$ for a rectangle with a perimeter of $760 \mathrm{cms}$., to $2 \cdot 28$ for one whose perimeter is $1050 \mathrm{cms}$, the gaps in the circles being about $15 \mathrm{cms}$. long to avoid any appreciable capacity effect due to the proximity of the ends of the circuit.

Comparing this result with that given just above for straight wires, it is found that the electrical vibration connected with a wire bent into the form of a circle, with a considerable gap in its circumference, has a shorter period than that associated with a straight wire of the same length. The actual result obtained is that a copper wire $0.33 \mathrm{~cm}$. in diameter, if bent into the form of a circular arc, with its ends separated by a distance of about $15 \mathrm{cms}$., requires to be $3 \cdot 2$ per cent. longer than a straight wire of the same gauge $310 \mathrm{cms}$. long to give a radiation of the same wave-length, and 3.4 per cent. longer than a straight wire $445 \mathrm{cms}$. in length. This result is to be expected when the ends of the circular are are not brought too closely together, as the inductance of the wire is less in the circular form than when straight and the capacity is practically unaltered (see Thomson, - Recent Researches,' \$ 385 ).

A further decrease of inductance without appreciable change of capacity can be made by bending the wire forming the open circle into the shape of a narrow rectangle with an open end. One would expect, therefore, the period of vibration in such a circuit to be somewhat less than that in an open circle of the same perimeter. That the periods of electrical vibration connected with such circuits are, at least, nearly equal when the perimeters are the same, is shown by a result obtained by Sarasin \& De la Rive* in connexion with their experiments with waves along wires. In these experiments it was found that the distance from the free ends of the wires to the first node was nearly equal to half the circumference of the resomator, and in such a case of parallel wires with free ends, the end section may be considered to correspond with an open rectangle. Macdonald, 'Electric Waves,' p. 121, in giving the distance to the first node from the end of the wire as $0 \cdot 192 \lambda$, makes the ratio of wave-length

* Sarasin \& De la Rive, C. $R$. vol. cx. 1890. 
to perimeter of open rectangle $2 \cdot 60$, or the period of vibration in such a circuit longer than in the case of an open circle of the same perimeter. Bumstead, in the Am. Journ. Sci. vol. xiv. p. 359 (1902), investigates theoretically the reflexion of electric waves at the free ends of a paralle] wire system. If I understand the result aright, it means that the distance from the free end of the wire to the first node is always less than a quarter the wave-length along the wires by half the distance between them. This cannot be generally true.

Kiebitz (Ann. der Physik, v. 4, p. 872, 1901) has found the length of an open circle resonator when in tme with a straight-rod oscillator. The rod being $250 \mathrm{cms}$. long, $248 \mathrm{cms}$. was finally taken as the resonance-length for the open circle, a result slightly different from that given above, where the distance between the ends of the resonator was much greater than in Kiebitz's experiment.

Sarasin \& De la Rive, as the result of their final measurements*, give the wave-length of the vibration connected with open resonators, made of stout wire $1 \mathrm{~cm}$. in diameter, as $600 \mathrm{cms}$. for an open circle $234 \mathrm{cms}$. in circumference, and $400 \mathrm{cms}$. for one $156 \mathrm{cms}$. in circumference. This makes the wave-length 2.56 times the length of the circuit.

Macdonald, 'Electric Waves,' p. 111, in considering the question of stationary waves in open circuits, calculates the wave-length for any resonator, and finds for the fundamental mode of vibration, $\lambda_{0}=2.537$ where $l$ is the length of the circuit, a value in wonderful agreement with Sarasin \& De la Rive's conclusions. Apparently, according to theory, the wave-length is independent, within wide limits, of the diameter of the wire of which the resonator is made, and the ratio of wave-length to length of circuit independent of the size of the circle.

By extrapolation (see fig. 2) the present experiments give, for a circle $200 \mathrm{cms}$ in circumference, the ratio of perimeter of rectangle to length of circuit $2 \cdot 45$. This is less than the ratio of wave-length to circumference as given above by Sarasin \& De la Rive for a similar-sized circle and as calculated by Macdonald. In considering the difference it is necessary to remember that extra capacity effects at the ends of the resonator may not have been altogether negligible in Sarasin \& De la Rive's apparatus. On the other hand, the wavelength of the vibration connected with narrow rectangular closed circuits, made of wire of finite thickness, may be a little longer than their perimeters. Again, the wave-length

\footnotetext{
* Sarasin \& De la Rive, C. R. vol. cxv. p. 1280 (1892).
} 
may be affected by the diameter of the wire of which the resonators are made.

Closed Rings.-In Ann. der Physik, vi. 4, p. 741 (1901), Kiebitz shows how a filings-coherer may be used to determine the existence of electrical resonance. In one set of experiments, the coherer was placed across a gap in a circular resonator. The oscillator was a straight wire $77 \mathrm{cms}$. long. It is stated, as the result of these trials, that with such a resonator there is the best response when its length is equal to the wave-length of the radiation falling on it. This is asserting a little too much. The only statement justified by the experiments, on this point, is that the resonator gives the best response when its length is double that of the straightwire oscillator.

Kiebitz's resonator must be considered a completely closed ring, and his experiment proves the possibility of inducing oscillations in connexion with such a circuit. The present experiments give a result not differing greatly from that just staced.

Turpain (Journ. de Pliys. vol. x. p. 434, 1901), from experiments with the resonator inclosed in an exhausted glass tube, says:- "If one completely closes the gap no current circulates in the closed circuit which the resonator presents. The electric density is zero at every point of the circuit at each instant." In view of Kiebitz's experiment this statement must be considered inaccurate.

The result of the present experiments on closed rings may be stated as follows:-Taking as a standard the period of the electrical vibration associated with a narrow rectangular closed circuit, where the longer side of the rectangle is parallel to the direction of propagation of the waves, an elliptical closed circuit of very small eccentricity, with its major axis parallel to the same direction, may be considered to have the same period of electrical vibration if its perimeter is equal to that of the rectangle. If the eccentricity of the ellipse is increased, the perimeter has to be decreased to keep the period of vibration unaltered, until in the limit, when the form becomes circular, the ratio of the perimeter of the rectangle to the circumference of the circle becomes $1 \cdot 11$ for a circle $800 \mathrm{cms}$. in circumference, the circle being made of copper wire $0.33 \mathrm{~cm}$. in diameter, and the rectangle, $30 \mathrm{cms}$. wide, of thin brass wire $0.04 \mathrm{~cm}$. thick. If the form of the circuit is further altered, so that the major axis of the ellipse becomes at right angles to the direction of propagation of the waves, the perimeter has to be further decreased to keep the period unchanged. 
Pocklington (Proc. Camb. Phil. Soc. vol. ix. p. 324, 1897) has calculated theoretically the period of the free electrical vibration associated with a closed circular ring, and has arrived at the result that the wave-length is rather less than the circumference of the circle. Kiebitz's experiment and the present investigation give a value rather greater than the circumference. The problem of the electrical oscillations connected with closed circnits is discussed generally by Macdonald ('Electric Waves,' p. 62), but calculations for special cases are not given.

Diameter of the Wire forming the Circuits.-St. John, in experiments with waves along wires (Phil. Mag. vol. xxxviii. 1894), for oscillations of the same period, obtains a 5 per cent. increase in the value of the wave-length along parallel copper wires as the diameter of the wires changes from $0.04 \mathrm{~cm}$. to $0.12 \mathrm{~cm}$. In St. John's investigation, however, the problem is complicated by the presence of extra capacity at the ends of the circuit. No difference of period has been found in the present experiments between a rectangle made of thin brass wire $0.04 \mathrm{~cm}$. in diameter and one of copper wire $0.33 \mathrm{~cm}$. thick. An open circle was compared with the rectangles in turn, and was in tune with each of them when its circumference was $380 \mathrm{cms}$, the perimeter of each rectangle being $886 \mathrm{cms}$. and the width $30 \mathrm{cms}$.

Permeability of the Medium surrounding the Circuits.-With the rapid alternations of current used in these experiments, it is not to be expected that the permeability of the material of the circuit would have a considerable effect on the period of vibration (see St. John, loc. cit.). The permeability of the medium ontside the wire, on the other hand, is of primary importance in this connexion. This may be readily shown by surrounding the middle portion of an open circuit, where the current is concentrated, when electrical oscillations take place in it, with fine, well-insulated iron filings, and comparing the period of vibration with that connected with the circuit in air. In the case tried, the central part of a straight copper wire $0.33 \mathrm{~cm}$. in diameter, covered with paraffined paper, passed centrally through a glass tube $70 \mathrm{cms}$. long and $1 \mathrm{~cm}$. internal diameter, the tube being filled with paraffined iron filings. The wire under these circumstances when $345 \mathrm{cms}$. long had the same period of electrical vibration as a copper wire of the same gauge wholly in air $370 \mathrm{cms}$. long.

\section{Results of present Investigation.}

In the following Tables, under the headings "perimeter of" rectangle" and "length of straight (or curved) wire," the

Phil. Mag. S. 6. Vol. 7. No. 42. June 1904. 2 X 
respective lengths of the two circuits when the electrical oscillations connected with them are in unison, are placed in the same row, the fundamental mode of vibration only being investigated. The rectangles have been made with sides of thin brass wire $0.04 \mathrm{~cm}$. in diameter, the ends being of copper wire $0.33 \mathrm{~cm}$. thick. The other circuits have been constructed wholly of copper wire $0.33 \mathrm{~cm}$. in diameter. From the result of an experiment described above, I believe both circuits may be considered to have been formed of the copper wire. The rectangles were in all cases $30 \mathrm{cms}$. wide.

Three methods have been used in the determinations. The results by the final one are considered of much greater weight than those by the earlier methods, and the observations have therefore been divided in the tables.

TABLE I.-Straight Wires.

\begin{tabular}{|c|c|c|c|}
\hline \multicolumn{2}{|c|}{ Length of straight wire. } & \multirow{2}{*}{$\begin{array}{c}\text { Perimeter of rectangle } \\
\text { in tune with straight } \\
\text { wire. }\end{array}$} & \multirow{2}{*}{$\frac{\text { Perimeter of rectangle. }}{\text { Length of straight wire }}$} \\
\hline $\begin{array}{c}\text { Final } \\
\text { method. }\end{array}$ & $\begin{array}{l}\text { Earlier } \\
\text { methods. }\end{array}$ & & \\
\hline \multirow[t]{2}{*}{310} & & 760 & 245 \\
\hline & 355 & 860 & $2 \cdot 42$ \\
\hline \multirow[t]{2}{*}{370} & & 886 & $2 \cdot 40$ \\
\hline & 400 & $95 \dot{5}$ & $2 \cdot 39$ \\
\hline \multirow[t]{2}{*}{445} & & 1050 & $2 \cdot 33$ \\
\hline & 500 & 1165 & $2 \cdot 33$ \\
\hline 520 & & 1200 & $2 \cdot 31$ \\
\hline
\end{tabular}

The relation connecting the above observations is shown graphically in fig. 1.

Open Circles. -The ends of the circles were bare and were separated by a distance of about $15 \mathrm{cms}$., so as to avoid any appreciable capacity effect due to their proximity. A result given by Close at the end of this paper, shows that in separating the ends of a bare-ended resonator, 15 2 cms. in circumference, made of copper wire $0.33 \mathrm{~cm}$. in diameter, practically no change is made in the period of vibration when the distance between them exceeds $8 \mathrm{cms}$. The actual length of the wire is given in the table under the heading "length of circular arc." 
Electrical Vibrations associated with Simple Circuits. 643

Fig. 1.-Straight Wires.

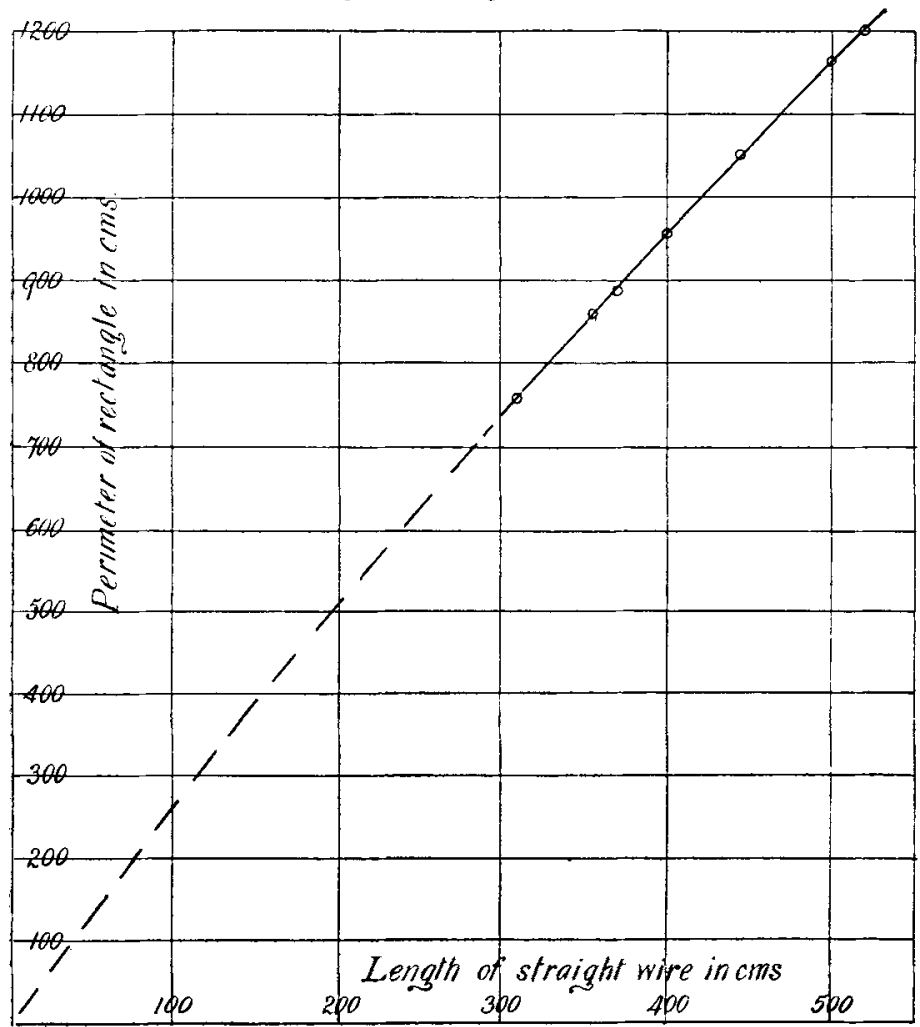

Table II.-Open Circles.

\begin{tabular}{|c|c|c|c|}
\hline \multicolumn{2}{|c|}{ Length of circular arc. } \\
$\begin{array}{c}\text { Final } \\
\text { method. }\end{array}$ & $\begin{array}{c}\text { Earlier } \\
\text { methods, }\end{array}$ & $\begin{array}{c}\text { Perimeter of rectangle } \\
\text { in tune with circular } \\
\text { are. }\end{array}$ & $\begin{array}{c}\text { Perimeter of rectangle. } \\
\text { Length of circular arc. }\end{array}$ \\
\hline 320 & & 760 & $2 \cdot 38$ \\
380 & 450 & 1030 & $2 \cdot 33$ \\
& & 1050 & $2 \cdot 30$ \\
460 & & $2 \mathrm{X} \mathrm{2}$ & $2 \cdot 28$ \\
\hline
\end{tabular}


The relation connecting these values is shown graphically in fig. 2 .

Fig. 2,-Open Circles.

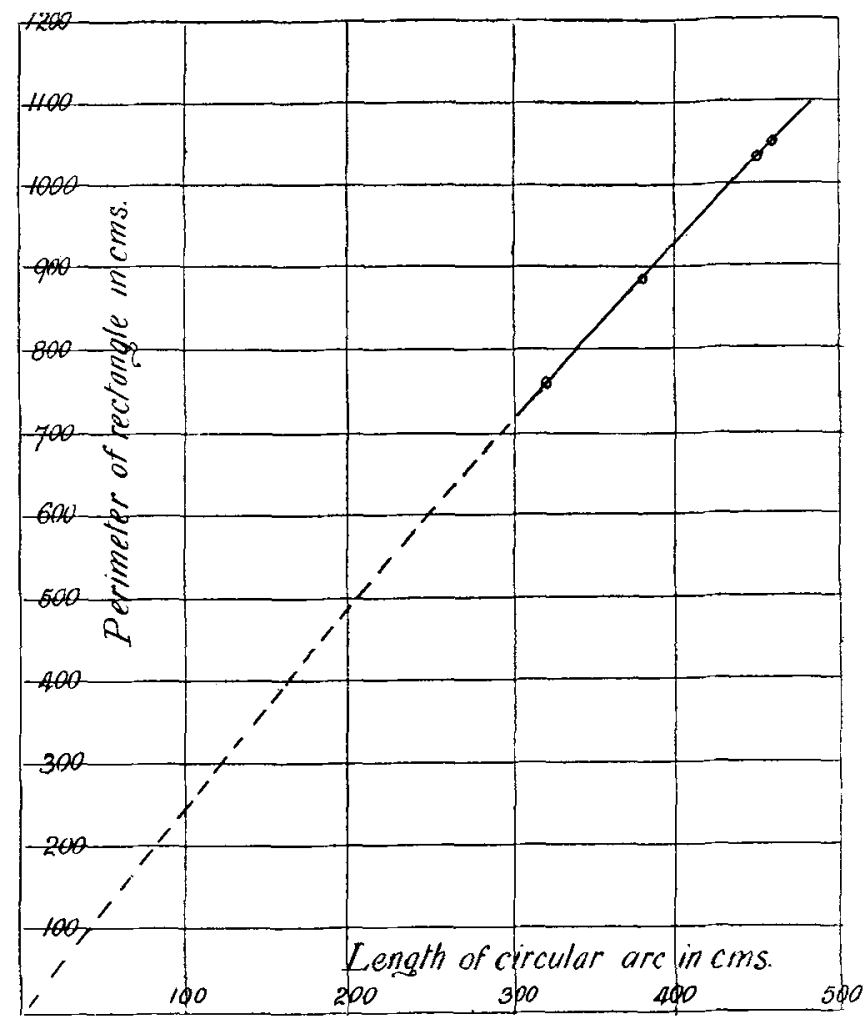

Closed Cireuits.-In the case of other than circular circuits no attempt was made to make the shape truly elliptical, and they must be considered merely as ovals approximating to the elliptical form. The perimeter and the ratio of the major and minor axes, given in the table, sufficiently indicate their shape. The ratio given is the length of the axis parallel to the direction of propagation of the waves along the circuit to the length of the axis perpendicular to this direction.

The relation connecting the values obtained for closed circles is shown graphically in fig. 3 . 
Electrical Vibrations associated with Simple Circuits. 645

TABLe III.-Closed Circuits.

Perimeter of circuit.

Ratio

of

\begin{tabular}{c|c}
$\begin{array}{c}\text { Final } \\
\text { method. }\end{array}$ & $\begin{array}{c}\text { Earlier } \\
\text { methods. }\end{array}$ \\
\hline
\end{tabular}

$678 \quad 850$

$2 \cdot 37$

$2 \cdot 33$

1.00

1.00

$1 \cdot 00$

069

0.56

0.53

0.28
Perimeter of circuit.

Perimeter of rectangle Perimeter of rectangle.

in tune with circuit. Perimeter of eircuit.

Fig. 3.-Closed Circles.

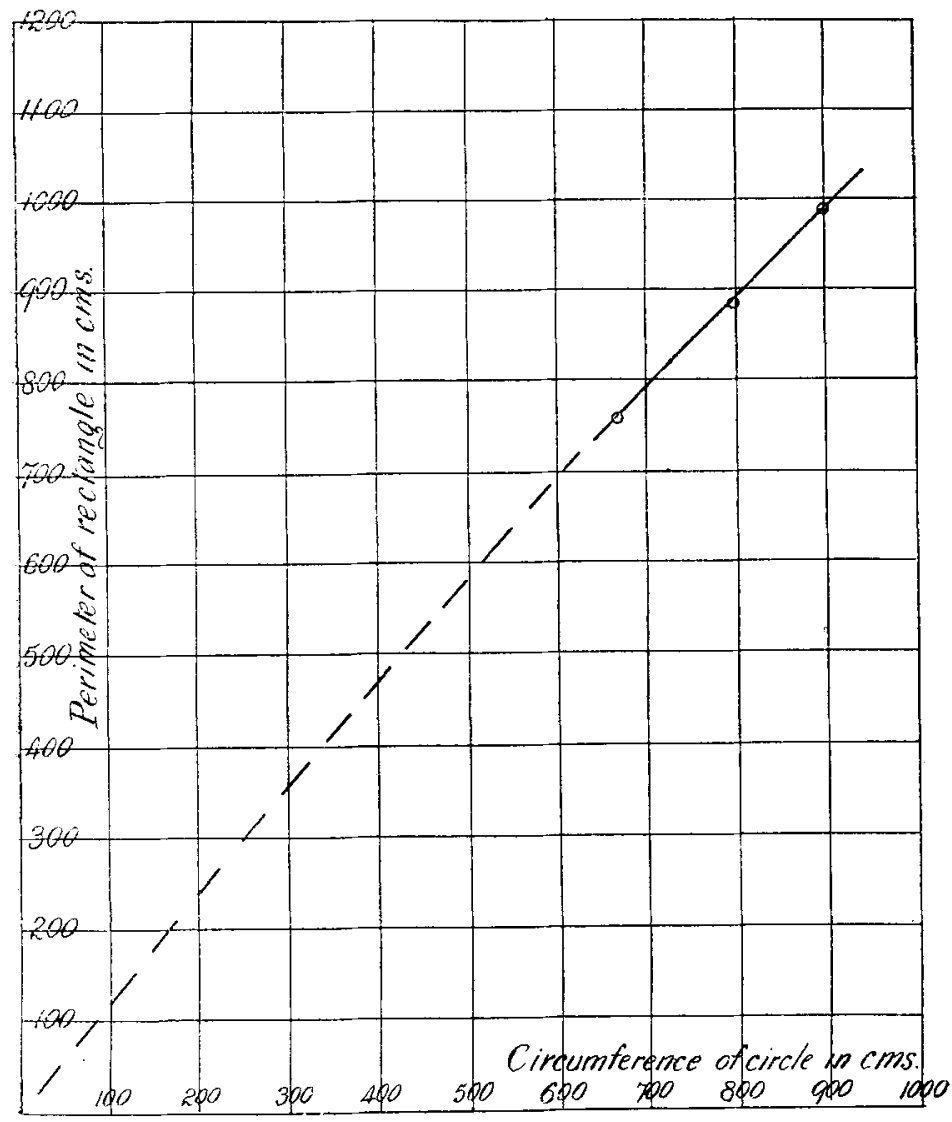


Experimental Details.

Three methods have been used in this investigation. In the first, a condenser $\mathrm{C}$, with a discharge circuit $a \boldsymbol{a}$, is arranged as indicated in fig. 4 , the diagram not being drawn to scale.

Fig. 4.

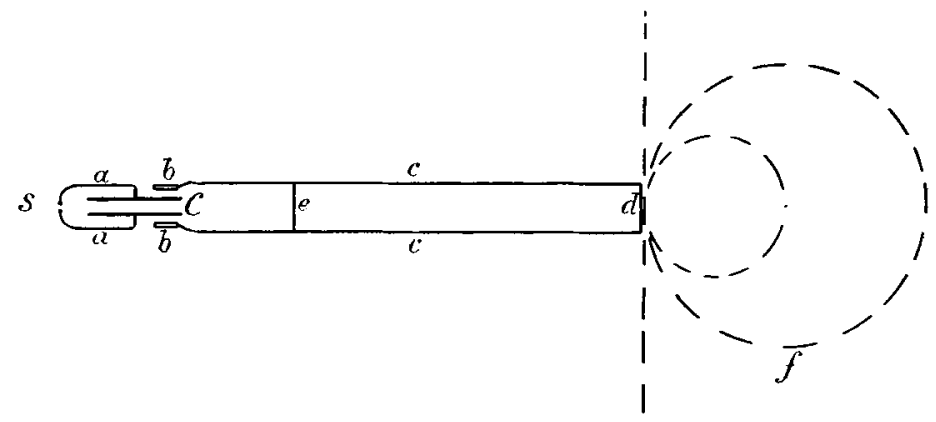

The condenser-plates are attached to wooden stands, one of which can be moved by a screw, the two condenser-plates always being strictly parallel. One of the discharge-wires is cut and connexion remade through a pool of mercury. This enables the condenser-plates to be set at any distance from each other without disturbing the spark-gap $s$. Two small hollow brass boxes, $b b$, are placed close to the condenserplates. The boxes are provided with pegs which can be turned from the outside. To these pegs parallel wires are attached, the wires coming out through holes in the sides of the boxes. This arrangement of wires leading into hollow boxes was used by St. John *, and it enables the length of the wires to be conveniently altered without changing the capacity of the system near the condenser-plates.

The wires are bridged at their ends and at some other point as at $e$. At a distance of $1 \mathrm{~cm}$. from the terminal bridge is placed a third circuit $f$, whose vibration period it is desired to compare with that of the rectangle formed by the parallel wires and the two bridges. In fig. 4 the position of various third circuits used is shown in dotted lines.

A preliminary investigation has to be made to determine the relation between the length of the wires $c c$ and the distance between the condenser-plates when the wire system and the condenser circuit are in tune. The procedure is as follows:-With a given length of the wires, observations are taken of the waves along them, due to a discharge of the

* St. John, Phil. Mag. vol. xxxviii, (1894). 
condenser, for different distances between the condenserplates. That position of the condenser-plates is sought which is connected with the strongest vibration in the wire system with three nodes in its whole length. The investigation is madefor various lengths of the wires, and curves are then drawn, so that for any wire-length the position of the nodes may be known, and the distance between the condenser-plates found which makes the condenser circuit in tune with the wire system. The characteristics of the waves along the wires are determined by the use of the magnetic detector invented by Rutherford, and described by him in the Phil. Trans. clxxxix. (1897) p. 8. The method is the same as that given by the author and Vonwiller in a paper on "Some Experiments on Electric Waves in Short Wire Systems," published in the Phil. Mag. for June 1902.

To determine the length of a circuit of given shape which has the same period of electrical vibration as that of a reetangle, the circuit is placed behind the bridge $d$, as shown in fig. 4 , with a portion of it, at which is situated a current loop, parallel to the bridge at a distance of about one centimetre from it. In some experiments the terminal bridge has been removed and the ends of the parallel wires attached directly to. the third circuit. The results have been the same in both instances.

In the case of straight wires, two small insulating tubes are placed symmetrically on the wire usually about $200 \mathrm{cms}$. apart. Each tube is encircled by a single loop of wire, the loops being attached by fine wires to mercury cups in a piece of hard rubber placed a little behind the middle of the straight wire. so that the ends of the solenoid of the detector may be joined to them. Readings with the detector are now taken on discharging the condenser, for various lengths of the parallel wires. At each adjustment of the length, the position of the bridge on the wires, and the distance between the condenser-plates, are altered by reference to the curves obtained in the preliminary investigation, so that the condenser circuit is always kept in tune with the parallel wire system. When the amplitude of the vibration in the straight wire is a maximum under these circumstances, as determined by observations with the detector, the wave-length of the vibration connected with the straight wire is considered to be the same as that associated with the rectangle formed by the parallel wires and the two bridges. Experiments with the other circuits have been made in a similar manner. A complete set of results was obtained by this method.

A second plan has been to set the condenser circuit and the 
parallel wire system in tune with each other, and keeping this part of the apparatus fixed, to alter the length of the third circuit by successive steps of 10 or $20 \mathrm{cms}$. From a plot of the observations of the disturbances in the third circuit, its length when it is in tune with the rectangle may be found. This method is more satisfactory than the former one in that each successive step involves the alteration of only one of three circuits, instead of two as in that case.

In repeating the experiments by this method, the plots of the observations showed more decided maxima. When the repetition was practically completed, owing to greater accordance among the observations due to the improvement in the character of the spark resulting from greater experience in the preparation of the spark knobs, two maxima close together were noticed in the plot of the observations with one of the straight wires. As the position of the maxima could be altered by changing the condenser-plate distance, the observation pointed to a want of success in tuning the condenser and rectangular circuits, an operation of considerable difficulty, and threw doubt on the accuracy of all the previous work.

It was decided therefore, after consideration, to do away with the hollow boxes attached to the rectangular circuit, which complicate the operation of tuning, and simply place the narrow end of a fixed rectangle near the spark-gap of the condenser circuit. The tuning of the condenser and rectangular circuits now involved only a change of the condenserplate distance. This operation was performed for three rectangles of different perimeters. It was found, however, that a want of tune between the condenser and rectangular circuits could be better detected by observations of the disturbance in the third circuit than of that in the rectangle itself.

The following procedure was finally adopted as giving the most definite results:-For a given distance between the condenser-plates, observations are taken of the disturbances in the third circuit while altering its length by successive steps. This series of observations is repeated for various distances between the condenser-plates. The plots of the observations show the relation between the disturbance in the third circuit and its length for various condenser-plate distances. That distance between the condenser-plates in connexion with which the plot shows the most definitely marked maximum, and in which the observations are perfectly symmetrical round this point, is taken as the distance which makes the condenser circuit in tune with the rectangle.

This operation of tuning the circuits is a tedious one; it has involved in some cases the comparison of fifteen complete 
curves drawn from observations obtained as just described. Once the circuits are tuned, the series of observations, necessary for a determination of the length of a third circuit when in tune with the rectangle, need only be repeated until the chance of a fortuitous accordance of the observations is eliminated.

Typical examples of the curves obtained are given in fig. 5 . The ordinates represent the difference of reading in cms. of the deflexions caused by the detector before and after demagnetization; they are proportional to the magnitude of the disturbances in the third circuit. Abscissæ represent the length of the third circuit, observations being usually taken for successive lengths differing by $20 \mathrm{cms}$. As the demagnetization of the detector depends, cateris paribus, on the length of the spark, such curves are only wholly comparable when they represent observations taken with the same spark-gap.

In fig. 5, curve 1 is a plot of observations taken in connexion with one of the straight wires, using the solenoidal

Fig. 5.

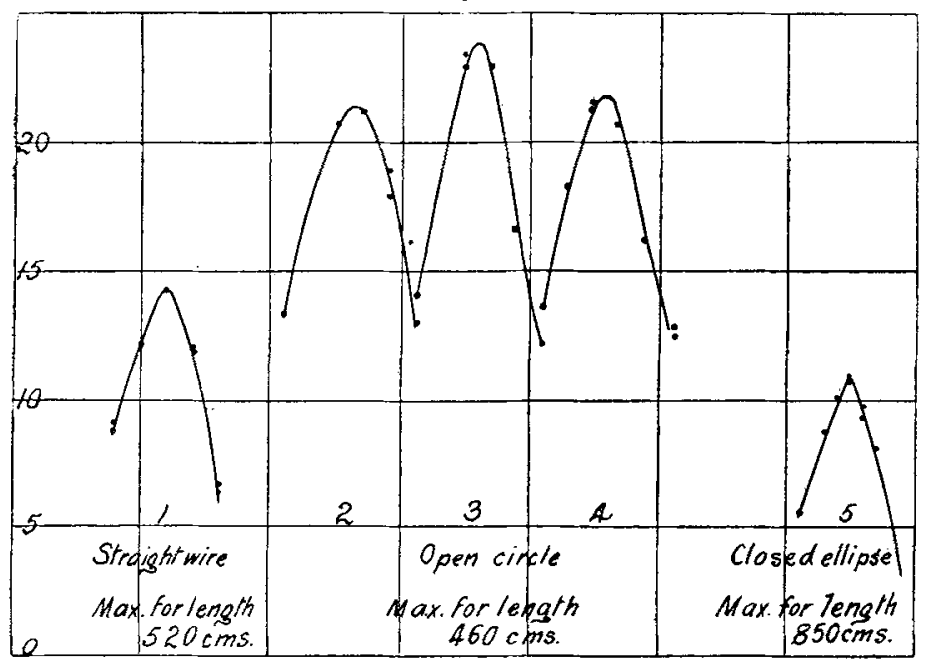

detector. Curves, 2,3 , and 4 refer to the case of one of the open circles. They are the plots of series of observations, without alteration of spark-gap, taken with condenser-plate distances successively increased by $0.1 \mathrm{~cm}$., the solenoidal detector being used. For tuning the condenser and rectangular circuits thirteen such curves were obtained, the series being extended and repeated three times to avoid any chance accordance of the observations. Curve 5 is a plot of observa- 
tions with a closed ellipse using the longitudinal detector (see infra). In this case the observations near the maximum are taken with ellipses differing in perimeter by $10 \mathrm{cms}$.

The maximum is much more definitely marked in the case of open circles than in circuits of other shapes, and here a want of tune between the condenser and rectangular circuits seems to have less effect in altering the character of the curve of the observations than in other cases. It has been found a more difficult matter to get a series of accordant observations with closed circuits than with open ones.

The Sparks in the Condenser Circuit.-Practically the only difficulty in connexion with the determination of numerical relationships in the case of Hertzian waves of small wavelength, lies with the spark which discharges the condenser. Many forms of detector are completely reliable. On the other hand, the character of the sparks is so variable and the conditions which determine it at present so obscure, that chance seems to enter largely into these investigations. Many spark-knobs have had to be tried in some cases in this research before the observations became quite accordant. To obtain a more uniform effect, a series of sparks may be taken for each observation, a method which has been used by many experimenters. As is well-known, however, only a limited number of sparks can pass between the knobs before the character changes owing to the deterioration of the discharge surfaces. In the present case, after trial, it was on the whole considered best to discharge the condenser once for each observation.

The condenser was charged from the secondary of a small induction-coil. The primary circuit of the coil was closed and opened by two keys worked by a heavy pendulum, the interruption taking place very quickly. The circuit was opened in air, the gap being short-circuited by the condenser of the coil. A variable resistance was inserted in the primary circuit, and adjusted so that when the spark-knobs were set, the difference of potential established on working the coil was just sufficient to break down the dielectric.

If the spark-gap is watched through a lens, as in these experiments for each discharge, it is seen that successive sparks jump across the gap from different points of the knobs. Their character may be either round, long, or irregular, either large or small, single or double, scarcely ever quite the same for two sparks together. The demagnetization of the detector has been found to so greatly depend on the path of the spark and on its character, that it was useless to retain any observations except in those cases where the sparks passed across the centre of the gap, and where the character was as far as could be 
Electrical Vibrations associated with Simple Circuits.

judged the same for all. Hundreds of observations have been rejected on account of irregularity of the spark. On the other hand, hundreds of discharges, where the sparks looked perfect, have given results utterly non-accordant.

For the earlier of these experiments the sparks passed between aluminium spheres $1 \mathrm{~cm}$. in diameter. The spheres were constantly repolished and were immersed in a large bath of paraffin-oil kept well stirred. A considerable improvement resulted on replacing the aluminium spheres by small spheres of platinum made by rounding the ends of platinum wires $0 \cdot 13 \mathrm{~cm}$. in diameter in the oxyhydrogen flame. With a flame not too hot and with patience, little hemispheres can be finally obtained on the ends of these wires whose surface and figure seem to leave nothing to be desired. About 30 sparks can in general be taken from such ends, though many more in some cases before they require to be re-fused. In some few instances series of observations have been obtained accordant among themselves, but differing from another series with the conditions unaltered. This has been due no doubt to the apparently chance nature of the character of the spark. No result has been retained which has not been fully confirmed by repetition.

The Detectors.-For the majority of the observations, and particularly for the final ones, Rutherford's solenoidal detector has been used. In the later experiments with straight wires where the length of the wire is altered, keeping the loops of the fine wires attached to the detector at a fixed distance apart on the straight wire, as described above, tends to increase the reading for shorter lengths. Such action has been found not to affect the result. In the experiments with open circles, the loops of the detector-wires were always at the ends of the circular wire, and in those with closed cireuits always at the ends of a diameter at right angles to the long side of the rectangular circuit.

To show that the length of the detector-wires does not influence the result of an experiment, the following trials were made with a straight wire :-(1) The wires to the detector, each $100 \mathrm{cms}$. long, once looped round an insulating tube on the straight wire; (2) wires each $40 \mathrm{cms}$. long soldered to the straight wire ; (3) wires $25 \mathrm{cms}$. long soldered to the straight wire ; (4) wires $10 \mathrm{cms}$. long soldered to the straight wire. In each case the observations gave the same result, the straight wire $400 \mathrm{cms}$. long being in tune with a rectangle $955 \mathrm{cms}$. in perimeter.

Further, an exhaustive comparison has been made between the results given by the solenoidal detector and those obtained with Rutherford's longitudinal detector. The latter was made 
of a piece of pianoforte steel wire $5.5 \mathrm{cms}$. long which had been dissolved in acid until its diameter was $0.014 \mathrm{~cm}$. The ends of the steel wire were soldered to two pieces of copper wire each $1 \mathrm{~cm}$. long and $0.33 \mathrm{~cm}$. in diameter. The wire was then firmly fixed by means of the copper ends in a glass tube, the copper pieces projecting a few millimetres beyond the ends of the tube. In an experiment the detector, after being magnetized to saturation, replaced a similar length cut from the middle portion of the circuit under investigation. Connexion was made by amalgamating the copper ends which were in contact, excess of mercury always being present. The magnitude of the disturbance in the third circuit is estimated by its demagnetizing effect on the steel wire, the detector being placed after magnetization and demagnetization in a geometrical clamp with one of its poles close to the magnet of a magnetometer.

The results obtained with the longitudinal detector, in no less than 16 cases, are identical with those found with the solenoidal one, showing that the demagnetizations of the core of the latter are not affected in the present instance by any vibration peculiar to the detector circuit. This point has also been considered by Chant (Am. Journ. Sri. xv. p. 54, 1903). The circuits examined have been made of copper wire $0.33 \mathrm{~cm}$. in diameter; the increase of inductance due to replacing $5 \mathrm{cms}$. in the central part of the circuit by the fino steel wire seems to have been negligible.

It has been found in this research more difficult to work with the longitudinal detector than with the solenoidal one. The former requires more delicate bundling and a more sensitive magnetic arrangement for detecting changes of magnetization.

The experiments have been carried out in a room 10 metres long by 6 metres wide, bare with the exception of gas and water pipes round the room.

The Physical Laboratory, 'The University of Sydney, November 25 th, 1903 .

\section{APPENDIX.}

The Effect of Capacity at the Ends of a Circular Resonator. By J. C. Close, Deas-Thomson Scholar in Physics.

With a similar apparatus to that described on p. 646 of the above paper, but of sinaller dimensions, the vibrations connected with open circular resonators were compared with those of a narrow rectangular closed circuit. The resonators were made of copper wire $0.33 \mathrm{~cm}$. in diameter, and the wire was in all cases $152 \mathrm{cms}$. long. The rectangle was made of 
thin brass wire $0.04 \mathrm{~cm}$. thick, the width of the rectangles being $31 \mathrm{cms}$. The experiments were made by the first method, described on p. 647 , in which the length of the resonator is kept constant, the length of the parallel wires being altered by winding the wire into the little boxes. In an experiment the length of the parallel wires was altered by steps of 5 or $10 \mathrm{cms}$., and readings taken of the disturbance in the resonator, with a Rutherford solenoidal detector, on discharging the coudenser. The observations with the detector were plotted against lengths of rectangular circuit and a curve drawn freely through the points obtained. The crest of the curve has been taken as marking the length of the rectangular circuit when in tune with the open circle.

The sparks discharging the condenser passed between aluminium spheres immersed in paraffin-oil. In spite of Fig. 6.

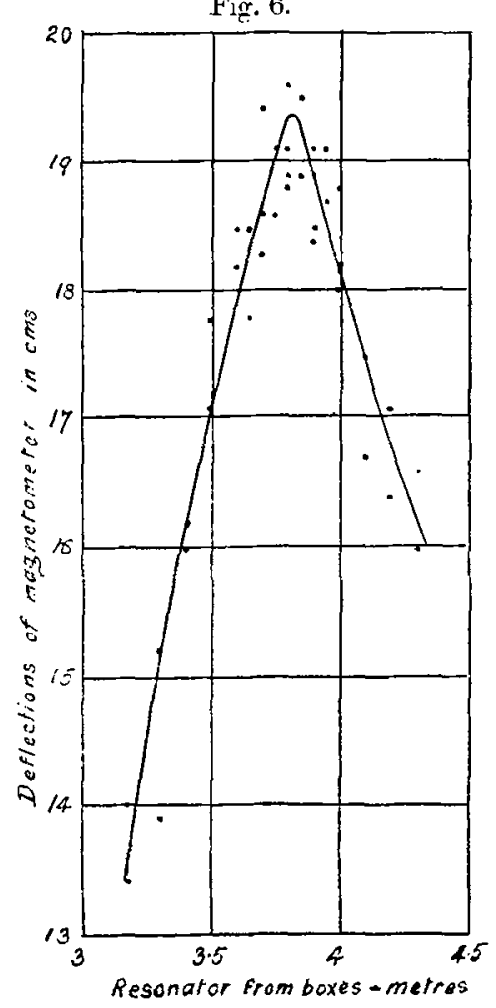

the fact that the discharge-surfaces were kept well polished, the sparks were not uniform in character; this accounts for the rariations in the readings. At least two sets of observations were taken in determining the position of each crest. A specimen curve is given in fig. 6 . 
Observations were first taken with a resonator with bare ends, the distance between them being varied from $0.05 \mathrm{~cm}$. to 4.7 cms. Two other resonators were tried, one with spheres $1.7 \mathrm{~cm}$. in diameter on its ends, and the other with spheres $2 \cdot 2 \mathrm{cms}$. in diameter, the length of the wire connecting the two spheres being $152 \mathrm{cms}$. long in both cases. The following is a table of the results obtained, the distance between the knobs being the length of the gatp in the circuit.

TABLE IV.

\begin{tabular}{|c|c|c|c|}
\hline Wire-length. & $\begin{array}{l}\text { Dirm. of spheres } \\
\text { at ends of wire. }\end{array}$ & $\begin{array}{l}\text { Distance between } \\
\text { surfaces of } \\
\text { spheres. }\end{array}$ & $\begin{array}{l}\text { Perimeter of } \\
\text { rectangle in tune } \\
\text { with resonator. }\end{array}$ \\
\hline $152 \mathrm{cms}$. & 00 & $0.05 \mathrm{cms}$ & $404 \mathrm{cms}$ \\
\hline$", \quad "$ & $"$ & $\begin{array}{l}3.05 \quad " \\
470 \quad "\end{array}$ & $\begin{array}{l}387 \quad " \\
387 \quad "\end{array}$ \\
\hline 152 " & $1.70 \mathrm{cms}$. & $0 \cdot 20 \quad "$ & $425 \quad "$ \\
\hline$" \quad "$ & 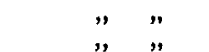 & $\begin{array}{l}0788, \\
9 \cdot 10,\end{array}$ & $\begin{array}{l}420 \quad ", \\
396 \quad "\end{array}$ \\
\hline 159 & 9.00 & $0 \cdot 20$ & 428 \\
\hline ", ", & $\begin{array}{c}200 " \\
20\end{array}$ & 0.78 & 493 \\
\hline$"$, & " " & $395 \quad$ & 404 \\
\hline
\end{tabular}

The relations between the values given in the above table are shown graphically in fig. 7 .

Fig. 7.
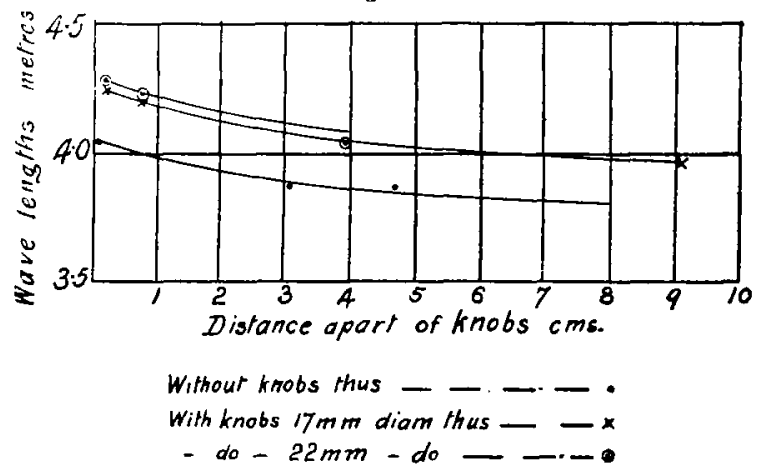

The curves show the effect of extra capacity at the ends of the resonator in increasing the period of the free vibration. The effect of bringing the ends of the resonator closer together is to increase the end capacity and hence the period. In separating the ends practically no change is made in the 
period of the free vibration when the distance between the ends exceeds $8 \mathrm{cms}$. Several attempts were made to determine the period of the free vibration of the resonator with bare ends close enough for a spark to pass between them, but they were unsuccessful.

The Physical Laboratory,

The University of Sydney,

December 8th, 1902.

LXXII. A Contribution to the Study of the Dielectric Constant of Water at Low 'Temperatures. By O. U. VonwILLer, B.Sc., Demonetrator in Plysics in the University of Sydney, N.S.W.*

7 THE experiments described in the following paper were carried out with the object of investigating the variation of the dielectric constant of water with temperature in the neighbourhood of $4^{\circ} \mathrm{C}$.

C. B. Thwing (Phys. Rev. ii. p. 35) carried out some experiments which apparently showed the existence of a critical point at $4^{\circ} \mathrm{C}$., the dielectric constant rising to a maximum value at that point and then decreasing as the temperature rose. On the other hand, Drude (Wied, Ann. lix. $1896^{\circ}$ ) and other experimenters have not observed such an effect.

The author's experiments were carried out with electrical oscillations having a frequency of about 25 millions per sec., produced in a Lecher wire-system by the oscillatory discharge of a condenser.

The arrangement of the apparatus is shown in fig. 1. A

Fig. 1.
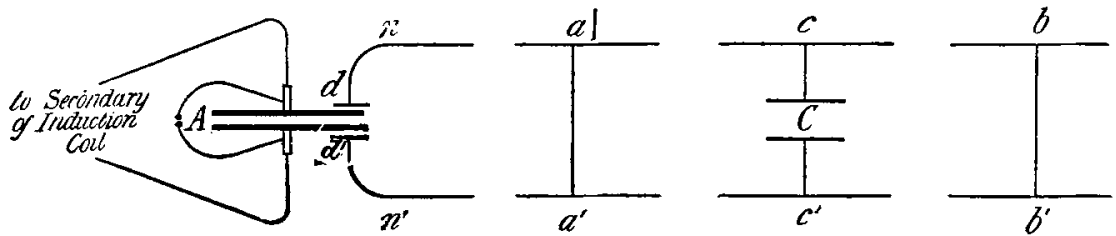

is a condenser consisting of two parallel circular brass plates, 30 centimetres in diameter, connected to the ends of the secondary of an induction-coil.

This condenser is discharged by means of a spark between two aluminium knobs immersed in kerosene, and joined to

* Communicated by the Author. Read before the Royal Society of New South Wales. 